\title{
Imparting the diagnosis of life threatening illness in children
}

\author{
H Woolley, A Stein, G C Forrest, J D Baum
}

TABL.E I - Diagnoses in 53 children (eight families had two affected children )

Cerebral degenerative disorder Diagnosis known Diagnosis unknown Brain tumour

Mucopolysaccharidosis Neuromuscular disease Other neoplasm Other

Department of Psychiatry, Warneford Hospital, University of Oxford, Oxford OX3 7JX

$\mathrm{H}$ Woolley, BA, research associate

A Stein, MRCPSYCH,

Wellcome trust lecturer

Park Hospital for Children, Headington, Oxford

G C Forrest, MRCPSYCH, consultant child psychiatrist

Institute of Child Health, Royal Hospital for Sick

Children, Bristol

J D Baum, MD, professor of child health

Correspondence to: $\mathrm{Ms}$ Woolley.

BrMed f 1989;298: 1623-6

\begin{abstract}
The parents of children with life threatening or terminal illnesses were interviewed about their experiences of the way in which they were told the diagnosis. The interview was piloted on 25 families and then administered in a semistandardised manner to a further 45 families. Parents were asked how satisfied they were with the initial discussion about the diagnosis: 23 families were satisfied with how much information they were given; 22 with the information concerning prognosis; 20 with the pacing of the information; 33 with who was present; 32 with arrangements for follow up; and 26 were satisfied overall with the initial discussion. Clear patterns emerged about which elements of the discussion parents appreciated or resented. For example, they valued an open, sympathetic, direct, and uninterrupted discussion of the diagnosis in private that allowed sufficient time for them to take the news in and for doctors to repeat and clarify information. They disliked evasive or unsympathetic brief interviews. All parents remembered vividly the manner in which the diagnosis was imparted, and some were still preoccupied with this many years later.
\end{abstract}

Analyses were carried out to test the possibility that reports of satisfaction and dissatisfaction were a function of current depression and anxiety, but no evidence was found for this.

\section{Introduction}

While talking with parents during the pilot phase of a study on chronic and life threatening illness in children it became clear to us that the memory of the interview with the doctor over the initial diagnosis lived on, in some cases for years, with a vivid and almost disconcerting immediacy. Some parents were still feeling the impact, remembering details of words, movement, expression, and attitude, the manner and style of delivery, the information given or apparently withheld and by whom and to whom it was given, and in what place. This was so whether they thought that they had had a satisfactory or an unsatisfactory interview or even an experience of both when, for instance, a subsequent second opinion was sought. Parents identified the features of the interview that they valued and that had helped them at the time and in coping subsequently. They also remembered the features that they disliked and found deeply distressing at the time and which lived on afterwards. Many parents commented that the informing doctor had had an unenviable task, as they too had had to break the bad news to their own family and friends.

Communicating to parents the diagnosis of their child's life threatening illness is an important but underresearched subject: it puts families under great stress and may influence the course of anticipatory grief. There is evidence that anticipatory grief can start from the moment the diagnosis is known, and the manner in which that grief is experienced and responded to by others may be important in determining whether the grief is benign or harmful.' The trauma of learning the diagnosis may also vary according to the manner in which the doctor presents it. ${ }^{2}$

Most studies of this subject have concentrated on short term terminal illness and mental handicap. ${ }^{3.1}$ Studying the experiences of parents of children with muscular dystrophy, Firth found that a third of the parents were not satisfied with the way that the diagnosis had been communicated, and in only a third of cases were both parents present at the interview. ${ }^{14}$ Some aspects, such as giving full information and providing good follow up, were considered, but others were not-for example, how doctors determined whether parents had understood their initial explanation and whether more time and repetition would have been helpful.

These issues are difficult to study. A few studies have covered a range of life threatening illnesses and in a few semistandardised interviews have been used, but none has examined whether parents' current mental states may be colouring their reports. ${ }^{15}$

\section{Patients and methods}

The data were collected during a study of the effects on the family of chronic life threatening illness in children and on the influence of Helen House, the first hospice in Europe caring for children suffering from chronic life threatening conditions.

During a pilot study in which 25 families who were attending Helen House were interviewed what emerged consistently as most important was how the diagnosis had been communicated. Many families thought that the manner in which this was done had affected their ability to cope with the illness and come to terms with the child's impending death.

The main study was carried out with 24 families with children who had been referred to but had not yet attended Helen House and 21 families whose children were being cared for within the health service. Table I gives the diagnoses. Eight families had two affected children. The children's ages ranged from 1-17 years (mean 7.5 years), and the length of illness ranged from six months to 10 years (mean five years). Data were collected from all parents in the same way. The mother was interviewed in all cases and was the main informant, although in 25 interviews both parents were present. Parents were asked questions concerning how the diagnosis was initially communicated with a semistructured questionnaire, and once the topic had been introduced many parents spontaneously provided information as they described their experiences and feelings.

Families were asked specifically about their initial discussions with doctors concerning the diagnosis, 
where they were held, who was present, what specific information was imparted (particularly concerning prognosis), the "pacing" of the discussions, and whether further contact was arranged or encouraged. They were asked what they liked or disliked about the way each of these aspects was dealt with (table II).

TABLE II-Satisfaction over how they learned the diagnosis in 45 families

\begin{tabular}{lcc}
\hline & No & $\%$ \\
\hline Families satisfied about: & & \\
How much information given & 23 & 51 \\
Quality of information on prognosis & 22 & 49 \\
Pacing of information & 20 & 44 \\
Who was present at discussion & 33 & 73 \\
Follow up arrangement & 32 & 71 \\
Overall satisfaction with interview & 26 & 58 \\
\hline
\end{tabular}

They were also asked to complete the general health questionnaire, which is a well established measure of current psychological state. ${ }^{16}$ These questions were included as part of a larger questionnaire inquiring about families' functioning in general. The time of the study interview from the time of the diagnosis interview ranged from two months to 10 years, with most families having learnt the diagnosis within the preceding two years.

\section{Results}

\section{OVERALL SATISFACTION}

Among the 45 families interviewed, 26 (58\%) were satisfied overall with the way the diagnosis was initially communicated, whereas $19(42 \%)$ were dissatisfied. The satisfied families cited the doctor's openness, directness, and sympathetic understanding in presenting the findings. The word "trust" was repeatedly used, and if the doctor looked at them and greeted and addressed them by name this helped in generating both trust and a feeling of being respected at a time when they were feeling vulnerable. Every parent said that being given sufficient time was important; discussions varied greatly in length from a few minutes to a whole afternoon. The parents' satisfaction was not related to whether or not the informing doctor came from a local or regional hospital or a tertiary centre.

One father's description illustrates the best features of the initial communication

Following investigations the doctor gave us anfrank open explanation of the diagnosis: he gave us time and took us on board as parents. Although he gave us the news straight he didn't give us all the information at one go. He asked us back in a couple of weeks and we discussed the terminal bit then. We felt somewhat put out that he hadn't told us that before but looking back I think he believed we were not ready to take it all yet. We accepted what he told us and trusted him because of his manner. He was the one who always gave us the worst news and we were upset, but the stress is much less if you know the worst: it is more if you feel the truth is being hidden. If the doctor seems able to cope with the incurable bit you feel safe and safety and trust are essential if you are going to be able to take the news on board and accept it.

\section{INFORMATION}

We asked about the quality and quantity of information given at the initial diagnosis.

\section{Aetiology and clinical features}

Only 23 of the 45 families were satisfied with how much information they were given initially on the aetiology and clinical features of the child's condition. All parents wanted information early: some wanted details at the first discussion, others over two or three discussions. Parents reported varying degrees of readiness to absorb details, depending particularly on how long they had been worrying about their child's worsening condition, which ranged from six weeks to 10 years before the interview over the diagnosis; the longer the period of worry the sharper was their apparent readiness to take in details.

Most parents wished for some information about aetiology: locating a cause helped ease the common initial response of self blame or guilt. Many felt some relief (despite their distress) at having the illness named, the clinical features described, and the child's illness described in the context of the recognised condition. Four parents came away from brief interviews having taken in only the name of the illness, and their worry was increased after repeated visits to public libraries in a desperate search for information which partly misinformed.

\section{Prognosis}

Twenty two families were satisfied with the information given them on prognosis. Regardless of how much they wished for and were told initially, on looking back no parent had wanted to be protected from bad news. The general consensus was that imagining the worst was worse than knowing it. Three exceptions were the parents who had not expected serious illness.

All parents wished for some warning about the future. Once an illness was identified and if no curative treatment was available then the issues of deterioration and life expectancy arose. Some parents who had had long interviews reported that they had broached the subject of death, particularly the likely time, place, and nature of the death and who might be available to support them. Most parents had no direct experience of death and imagined the worst. Most wanted advice about what symptoms to expect, believing with hindsight that having been forewarned of the symptoms had helped them cope with the unknown future.

For some rarer conditions the doctors knew little about the prognosis. None the less parents preferred to be told that little was known rather than to be met with evasive comments.

\section{PACING AND REACTIONS OF PARENTS}

Twenty parents were satisfied with the pacing of the initial news. Parents believed that this had been determined at least in part by their own immediate responses. They described reactions of disbelief, shock, anger expressed as numbness, weeping, stunned silence, and fury. Fury emerged occasionally as an angry challenge to the informing doctor. In one case parents cited the doctor's ability to sit out the upset and the anger without responding as though it had been a personal attack as helping them to set up a working relationship. Parents said that their immediate shocked reactions affected their ability to hear and take in what was being said. Many reported that it was essential to be given sufficient time. It was especially helpful when doctors asked them what they had understood and then repeated and clarified points in different ways. In contrast, dissatisfied parents reported that they had been unable to understand terms and explanations and were given little time for clarification.

Most parents appreciated being given time together in private to take the news in and to share their feelings.

WHO ATTENDED THE INTERVIEW AND WHERE IT TOOK PLACE

All parents wanted the interview to be held in private where they would be neither overheard nor interrupted. Nine parents were told the diagnosis in a place where they could be overheard or in the presence of several unknown staff. In a third of the initial discussions only one parent was present (three were single parents). It was then difficult for one parent accurately 


\section{How parents wish to be told the diagnosis}

\section{Setting}

In private

Uninterrupted

Unhurried

Both parents present if possible

Manner

Establish initial contact

Show respect to family (they are vulnerable)

Call family by name

Do not avoid looking at them

Be direct, open, sympathetic

Information: flexibility is essential

Pace rather than protect from bad news

Name illness

Describe symptoms relevant to child's condition

Discuss aetiology - parents will usually want to know

\section{Prognosis}

Listen to parents' concerns about time, place, and nature of death

Outline available support throughout illness and death

Elicit what parents have understood

Clarify and repeat

\section{Follow up}

Acknowledge that it may be difficult for parents to absorb all information

Offer early follow up

Mention sources of support

If available give telephone number

Mention ward back up if available

Give address of self help agency

Ensure adequate communication of content

of interview to general practitioner and

health visitor and (if at tertiary centre) to

referring paediatrician

Allow sufficient time before the next appointment was helpful as was a summary letter of the discussion, the name and address of a society offering support and information about a specific illness, and outlining available support services. This eased some of their fears and lessened their sense of being alone. Overall, 32 were satisfied with follow up information and arrangements.
Single parents especially may wish to have relative present or a professional whom they know, such as the ward sister
CURRENT PSYCHOLOGICAL FUNCTIONING AND SATISFACTION-DISSATISFACTION

Some factors unconnected with the doctor's manner may have influenced parents' satisfaction, the most likely being their mental state at the time of our interviews. Analyses were carried out to test the possibility that reports of satisfaction and dissatisfaction were merely a function of current depression and anxiety, but no evidence was found for this. In particular no differences were found in the scores for the general health questionnaire between parents who were satisfied and those who were dissatisfied with the discussion of the initial diagnosis. The mean scores on the general health questionnaire for the mothers in the satisfied group was $18 \cdot 4$ (SD 15.1) and for mothers in the dissatisfied group $15.9(\mathrm{SD} 15 \cdot 7), \mathrm{t}=0.5$. No differences were found in the fathers' scores between the two groups.

If parents are ready, mention symptoms the child might experience during deterioration

Perhaps suggest to families that they write down questions in preparation for next appointment

\section{Discussion}

The consistency of the reports from parents of children with life threatening illnesses about what they found valuable and helpful and what they disliked about how they were told the diagnosis was striking. The memory of the quality of the discussion about the diagnosis did not seem to be coloured by the current mental state of the parents.

The amount of information that parents thought they could take in initially varied, and this argues for a sensitive and flexible response from doctors. None the less, recognising that some parents have been worrying about their child's symptoms for a long time may be useful when judging how to pace the discussion. The longer the period of worry the more prepared parents often were to accept fuller details about the diagnosis.

Acute worry can intensify and alter a person's sense of time. Some parents had worried for months, even years; but to those in distress even a week was remembered as a lifetime. Although deeply shocked and dismayed by such a diagnosis, parents often reported that they were relieved at knowing "at last" what they were up against, the emphasis being on the pacing of, rather than protection from, painful news. Being told the news early, directly, sympathetically, and in private was important: in 15 families only one parent had been seen, and in nine families parents were seen with several other professionals present who were unknown to the parents, or in a place where they could be overheard. When the information was repeated, clarified, and explained in straightforward language and they were given a list of support services parents felt more able to accept the diagnosis and were better prepared to deal with the future.

Confusion, disorientation, distorted recall, and memory lapses have been reported to occur during and after interviews over a diagnosis. ${ }^{9}$ But when doctors paced the information sensitively, took sufficient time, and repeated and clarified what they were saying many parents in this study reported that they took in and remembered what they were told initially even though they often needed further discussions to confirm what they remembered.

For these parents the interview with the doctor was the first crucial step in setting up a working relationship for managing and coping with the practical and emotional aspects of their child's illness and possible 
death. The enabling quality of this discussion helped them to "make the most of the limited time left."

Parents vividly remembered the doctor's response to their distress. The doctor's ability to accept and understand the parents' grief was important in establishing trust and shaping the future relationship. Feelings of anger, guilt, and sadness are well known to be part of the process of grieving, which may begin at the time of diagnosis when the fatal nature of the illness is confirmed. ${ }^{1 .}$ Parents may need help to work through their anger and sadness during this long and necessary grieving process. Schoenberg pointed out that "health professionals place great emphasis on the preservation of life and in general view the patient's death as a personal failure." And yet the physician is required to be "honest, consistent, supportive and sympathetic while maintaining the qualities of equanimity and imperturbability." The results of our study confirm that when the doctor showed these qualities when imparting the diagnosis of a life threatening illness it in fact sustained and supported the parents despite their deep distress, and the beneficial effects persisted, in some cases for many years.

We thank the families who so generously participated in the study; all who helped with the recruitment including the staff of Helen House Hospice; the many paediatric consultants; Dr Roger Burne; Carolyn Fordham Walker, Ann Day, and Pavlos Anastasiades for unstinting help; and Dr C Ounsted for comments on an earlier draft of the paper. The study was funded by the DHSS, The King Edward Hospital Fund and Help the Hospices.
1 Fulton B, Gottesman DJ. Anticipatory grief; a psychosocial concept reconsidered. Br f Psychiatry 1980;137:45-54.

Bozeman MF, Orbach CE, Sutherland AM. Pswchological impact of cancer and its treatment Cancer 1955:8:1-9.

3 Quine J, Pahl J. First diagnosis of severe mental handicap: characteristics of unsatisfactory encounters between doctors and parents. Soc Sci Med unsatisfactory

4 Greenberg LQ. Jewett LS, Gluck RS, et al. Giving information for a life threatening diagnosis: parents' and oncologists' perceptions. Am $\mathcal{F}$ Dis Child 1984:138:649-53.

5 Mulhern R, Crisco J, Camitta B. Patterns of communication among pediatric patients with leukemia, parents, and physicians: prognostic disagreements and misunderstandings. F Pediatr 1981;99:480-3.

6 Cunningham CC, Morgan PA, McGucken RB. Downs syndrome: is dissatisfaction with disclosure of diagnosis inevitable? Dev Med Child Neurol 1984;26:33-9

7 Sherman MD, Austrian RW, Shapiro T. Labeling and unlabeling: perception of diagnostic terms among mothers and professionals. I Dev Behav Pediat 1981;2:93-6.

8 Rockowitz RJ, Davidson PW. Discussing diagnostic findings with parents. Journal of Learning Disabilities 1979;12:11-6.

9 Koch CR, Hermann J, Donaldson $\mathrm{MH}$. Supportive care of the child with cancer and his family. Semin Oncol 1974;1:81-6.

10 Myers BA. The informing interview, enabling parents to "hear" and cope with had news. Am 7 Dis Child 1983:137:572-7.

11 Kaplan D, Grobstein R, Smith A. Predicting the impact of severe illness in families. Health Soc Work 1976;1:71-82.

12 Findlay II, Smith P, Graves PJ, Linton ML. Chronic disease in childhood: a study of families' reactions. British fournal of Medical Education 1969;3 66-9.

13 Wiener JM. Reactions of the family to the fatal illness of a child. In Schoenberg B, Carr AC, Peretz D, Kutscher AH, eds. Loss and grief: psychological management and medical practice. New York: Columbia University Press, 1970:87-101

14 Firth M. Diagnosis of Duchenne muscular dystrophy: experiences of parents of sufferers. Br Med f 1983;286:700-1.

15 Teasdale JD. Negative thinking in depression: cause, effect or reciprocal relationship? Advances in Behavior Research and Therapy 1983;5:3-25.

16 Goldberg D. The detection of psychiatric illness by questionnaire. Oxford: Oxford University Press, 1972

17 Schoenberg B. Management of the dying patient. In: Schoenberg B, Carr AC Peretz D, Kutscher AH, eds. Loss and grief: psychological management and medical practice. New York: Columbia Úniversity Press, 1970:238.

(Accepted 31 March 1989)

Lesson of the Week

\title{
Unrecognised high pressure chronic retention of urine presenting with systemic arterial hypertension
}

\author{
R R Ghose, V Harindra
}

Men over 50 with hypertension of recent onset should be investigated for high pressure chronic retention of urine

Singleton Hospital, Sketty, Swansea SA2 8QA R R Ghose, FRCP, consultant physician V Harindra, MRCP, medical registrar

Correspondence to: $\mathrm{Dr}$ Ghose.
Clinical and urodynamic assessment of chronic retention of urine shows that the condition may be subdivided into three categories. These are, firstly (80$85 \%$ of patients), low pressure chronic retention characterised by low bladder filling pressure and high voiding pressure from powerful destrusor activity, typically associated with bladder outlet obstruction from prostatic hypertrophy; secondly $(15 \%$ of patients), low pressure chronic retention with low bladder filling pressure and low voiding pressure from bladder hypotonia and weak detrusor activity; and, thirdly (about 5\% of patients), high pressure chronic retention with high pressure voiding arising from bladder outflow obstruction accompanying benign prostatic hypertrophy, prostatic carcinoma, bladder carcinoma, urethral strictures, and urethral valves.

High pressure chronic retention is important because of its tendency to produce uraemia and hypertension as a consequence of bilateral hydronephrosis. In contrast with low pressure chronic retention urological symptoms may be absent in advanced disease. In some cases late onset enuresis and a tense, painless bladder may be present. ${ }^{2}$ In a recent study $52 \%$ of patients with untreated high pressure chronic retention presenting to a urological clinic were noted to have diastolic blood pressures ranging from 95 to $120 \mathrm{~mm}$ $\mathrm{Hg}$. Bladder drainage for three days produced an increase in urine volume and sodium excretion with a fall in body weight accompanied by a reduction in diastolic blood pressure to $70-100 \mathrm{~mm} \mathrm{Hg}$. It was concluded that high pressure chronic retention may represent the commonest form of surgically correctable hypertension.

We describe six men who presented with moderate to severe hypertension, some of whom were resistant to antihypertensive drugs, and who were found to have high pressure chronic retention of urine. The effects of transurethral resection of the prostate on hypertension and renal function are examined.

\section{Patients and methods}

Six men aged 50-70 years (mean 62) were referred to a medical clinic because of hypertension. None complained of urological symptoms but questioning elicited a history of late onset enuresis for the past three months in two (cases 4 and 6). Both patients were found to have tense, painless bladders on palpation of the suprapubic region. Rectal examination disclosed a prostate of normal size and consistency in five patients, the remaining patient (case 3 ) having moderate enlargement.

Biochemical screening disclosed serum creatinine concentrations ranging from 133 to $409 \mu \mathrm{mol} / \mathrm{l}$ (mean 291). Imaging was performed with urinary tract ultrasonography, intravenous urography, and gammacamera renography. Full urological assessment was obtained. Glomerular filtration rate and effective renal plasma flow were estimated by standard isotope techniques. ${ }^{+}$Blood pressure was measured with a mercury 